\title{
The Capabilities of Doppler Current Profilers for Directional Wave Measurements in Coastal and Nearshore Waters
}

\author{
Rick Birch, David B. Fissel, Keath Borg, Vincent Lee and David English \\ ASL Environmental Sciences Inc. \\ 1986 Mills Road \\ Sidney, British Columbia, V8L 5Y3, Canada \\ rbirch@aslenv.com
}

\begin{abstract}
The adaptation of Doppler current profilers to measure directional wave spectra has provided a new instrumentation approach to coastal and nearshore oceanographic studies. Past studies have shown favorable comparisons between Doppler current profiler wave instruments with bottom mounted PUV (pressure-velocity) sensors sampling at wave frequencies and wave buoys. In this paper, we examine the capabilities and limitations of two different Doppler current profilers for directional wave measurements in shallow coastal waters of $0-25 \mathrm{~m}$ water depth. Data collection programs using Doppler current profilers for wave measurements have been conducted for one month long periods in the early spring of 2002, 2003 and 2004 on Roberts Bank in the Fraser River foreslope region of the Strait of Georgia, British Columbia, Canada. In 2004, an RD Instrument ADCP along with the newly-released $1000 \mathrm{kHz}$ Nortek AWAC current profiler and wave instrument were co-located in $7 \mathrm{~m}$ water depth at a different site on the edge of Roberts Bank. Inter-comparisons between these bottom mounted instruments are used to examine the capabilities of the directional wave spectral parameters, in terms of: resolvable frequencies for directional and non-directional wave spectra; wave directional resolution and reliability, and limitations arising from the use of linear wave theory. For a preliminary assessment of the capability of Doppler wave spectra in deeper waters of 20-25 m depths, in particular for very long wave periods, some experiences derived from a long-term measurement program being conducted off the west coast of Africa are presented.
\end{abstract}

\section{INTRODUCTION}

Measurements of directional waves in coastal zones are required in support of many applications including input to engineering design and operational planning for ports and marine terminals, sediment transport and beach erosion for scientific and engineering purposes and dispersal of pollutants from outfalls or accidental spills.

Traditionally, directional wave measurements are made with: (a) instruments which are complex to install such as capacitance wire gauges or distributed arrays of bottom pressure sensors, (b) directional wave buoys which tend to be expensive, are prone to damage/vandalism, and have mooring issues in shallow coastal waters or (c) bottom mounted pressure-velocity (PUV) sensors which are less expensive but are limited in effective working depths to less than $10-15 \mathrm{~m}$ due to the high degree of attenuation in the high frequency portion of the wave signal of pressure and velocity.
Acoustic Doppler Current Profiler (ADCP) instruments, which were first developed for remote measurements of current profiles in the 1980's, have been adapted to the measurement of directional waves over the past several years $[1,2,3]$ with initial tests conducted in comparatively shallow waters of 7-8 $\mathrm{m}$ depth. In these shallow waters, pressure sensors were also used along with the measurement of orbital wave velocities. Intercomparison studies have been extended to deeper waters using wave buoys [4,5], both directional and non-directional types. More recently, the capabilities of the Doppler Current Profiler wave instruments have been augmented through the use of acoustic surface tracking methods with upward looking sonars [6], which is not attenuated with depth as is the case of the wave orbital velocities and especially, bottom pressure.

Our purpose is to provide insights into the capabilities of Doppler Current Profilers for directional wave measurements based on:

(a) an inter-comparison of the RDI $1200 \mathrm{kHz}$ Doppler Current Profiler, using its Wave Array algorithm, along with surface tracking with a newly introduced Nortek 1000 kHz AWAC Doppler Profiler having an enhanced surface tracking capability, co-located in 7 $\mathrm{m}$ water depth, and

(b) some preliminary experiences of using a RDI 600 $\mathrm{kHz}$ ADCP for directional wave measurements in 20-25 m water depths in West Africa.

\section{INTERCOMPARISON OF NORTEK AWAC AND RDI ADCP}

\section{A. Location and Mooring}

Measurements of waves, currents and sediments have been conducted by ASL Environmental Sciences Inc. on the Roberts Bank foreshore portion of the Fraser River delta in the Strait of Georgia, British Columbia, Canada. As part of studies of sediment dynamics and transport on Roberts Bank, in 2002, PUV data collected with a 1000 $\mathrm{kHz}$ Nortek Aquadopp Doppler velocity instrument was compared to PUV data using a conventional electromagnetic current sensor in $10 \mathrm{~m}$ water depth [7]. In 2003, a 1200 kHz RDI Doppler Current Profiler using the "wave array" configuration, as well as surface tracking and pressure sensors for non-directional wave spectral measurements, was deployed in $8 \mathrm{~m}$ water depth [7]. In 2004, an intercomparison study using two different ADCPs was conducted as part of engineering and environmental studies related to the planned expansion of the Roberts Bank container terminal operated by the Vancouver Port Authority (VPA). Discussion of these 2004 intercomparison results will be the focus of this section. 


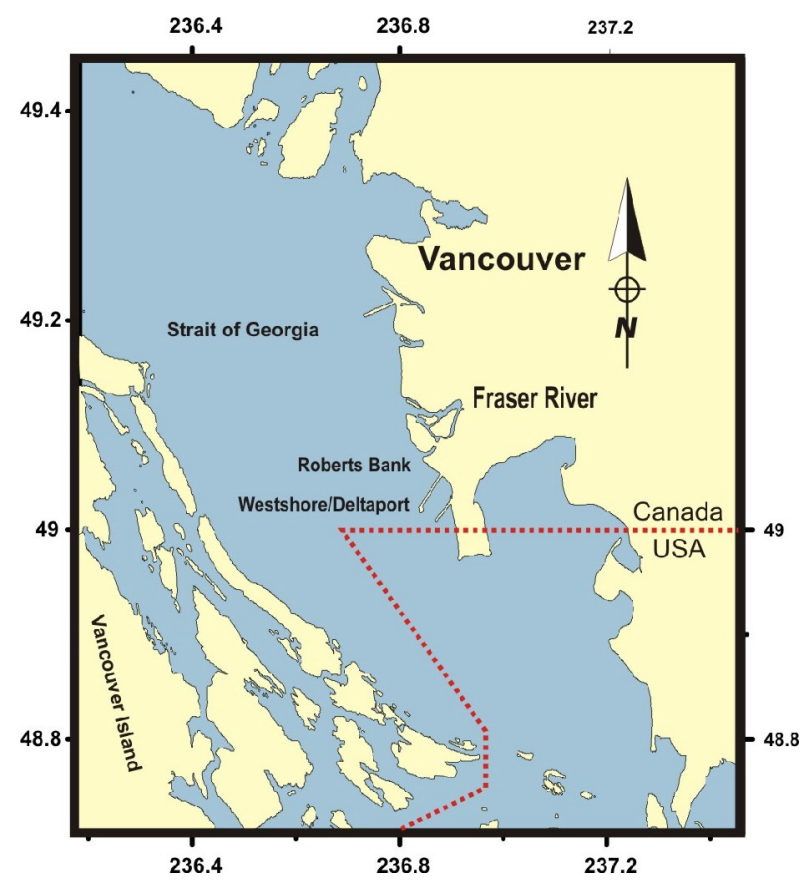

Fig. 1. Map of the southern Strait of Georgia and the Fraser River delta. The Westshore/Deltaport container terminal is at the end of the T-shaped causeway.

ASL is providing long-term representative wave and current data for the terminal expansion study. The container terminal is located on the Fraser River delta at the end of a causeway that extends across Roberts Bank (Fig. 1, 2). Deltaic deposits crowd the receiving waters of the Strait of Georgia, with water depths increasing to $200 \mathrm{~m} 10 \mathrm{~km}$ offshore. The Strait is aligned approximately northwest/southeast, which is also the two main directions for winter storm winds. The largest fetch is to the northwest, $80 \mathrm{~km}$.

The mooring was located on the edge of the Bank in $7.2 \mathrm{~m}$ water depth (relative to low tide). A diver-serviceable bottom frame was built to house both instruments (Fig. 3). This minimized the disturbance to the bottom since only the instrument cube is recovered for servicing, while the heavy base remains on bottom.

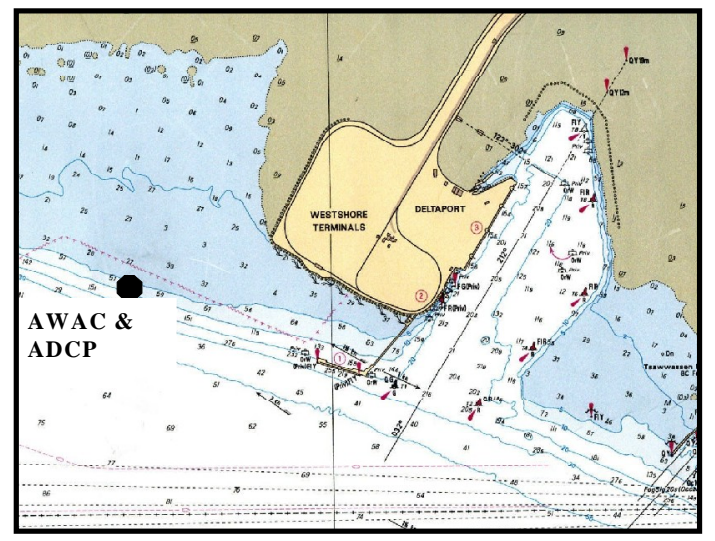

Fig. 2. Deltaport/Westshore Terminals. The location of the mooring $(\bullet)$ in $7.2 \mathrm{~m}$ water depth at the edge of Roberts Bank is shown. From CHS chart \# 3492.

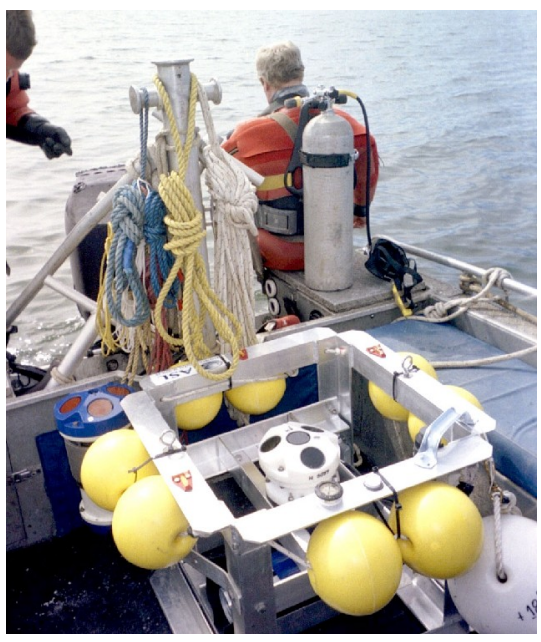

Fig.3. The diver serviceable bottom frame used to moor both the Nortek AWAC, and the RDI ADCP.

The instruments are always deployed in exactly the same location, which is important as the wave regime varies over short distance scales at this site on the edge of the Bank. Servicing is done at 3-month intervals with divers and a small boat. The divers level the cube to within a few degrees of vertical each time. Concrete pier blocks were added to the base to increase the weight. It is important when measuring waves in shallow water that the instrument is stable and does not respond to wave orbital velocities.

\section{B. Instrumentation}

Both a Nortek AWAC and an RDI ADCP were deployed to measure currents as well as directional waves (Table 1). The Nortek AWAC (Acoustic Wave and Current Meter) is a $1 \mathrm{MHz}$ 3-beam Doppler instrument that also has a vertical beam for direct measurement of the wave heights. An RDI $1200 \mathrm{kHz}$ WH ADCP instrument was also deployed for the 13 April - 3 June 2004 period. The RDI ADCP has the standard 4-beam configuration.

The Nortek AWAC uses Acoustic Surface Tracking (AST) for direct measurement of the wave heights. A receive window is defined, based on the pressure, and partitioned into multiple cells $(2.5 \mathrm{~cm}$ size). Then a short acoustic pulse is transmitted and a match filter applied over the series of cells to locate the surface. Quadratic interpolation is used to determine the surface location. Vertical resolution is stated to be about $1 \mathrm{~cm}$ or better. Sampling rates of up to $4 \mathrm{~Hz}$ allows high frequency wave resolution out to $2 \mathrm{~Hz}$. The frequency limitation is determined by a combination of the Nyquist frequency (0.5 times the sensor sampling rate) as well as being limited by the acoustic "footprint", i.e. when half the wavelength is on the order of the diameter of the footprint [4]. For the 7-10 $\mathrm{m}$ water depth (low-high tide), the frequency resolution due to the $22-30 \mathrm{~cm}$ footprint, is 1.9-1.6 Hz, for a sampling rate of $4 \mathrm{~Hz}$. Note that if the AST data are unreliable, wave heights can also be computed from the pressure, or velocity spectra.

Three other beams, at 25 degrees from vertical, are used to measure current profile and wave orbital velocities based on the Doppler effect. The depth of the cell for wave orbital velocity measurements is adaptively positioned for 
each wave measurement burst.

\begin{tabular}{|c|c|c|}
\hline & Nortek AWAC & RDI ADCP \\
\hline \multicolumn{3}{|l|}{ Transducers } \\
\hline Frequency & $1 \mathrm{MHz}$ & $1200 \mathrm{kHz}$ \\
\hline Orientation & $\begin{array}{l}\text { 3-beam convex, } \\
25^{\circ} \text { from vertical; } \\
\text { one vertical (AST) }\end{array}$ & $\begin{array}{l}\text { 4-beam convex, } \\
20^{\circ} \text { from vertical }\end{array}$ \\
\hline Beam Width & $1.7^{\circ}(3 \mathrm{~dB})$ & $1.4^{\circ}(3 \mathrm{~dB})$ \\
\hline \multicolumn{3}{|l|}{ Wave Data } \\
\hline Data types & $\begin{array}{l}\text { AST vertical beam } \\
\text { surface track; one } \\
\text { orbital velocity cell } \\
\text { along each beam; } \\
\text { pressure }\end{array}$ & $\begin{array}{l}\text { 4-beam surface } \\
\text { track; } 3-5 \text { orbital } \\
\text { velocity cells along } \\
\text { each beam; } \\
\text { pressure }\end{array}$ \\
\hline Samples/burst & 512,1024 or 2048 & variable \\
\hline Cell size & $0.4-4.0 \mathrm{~m}$ & $0.01-\geq 2 \mathrm{~m}$ \\
\hline Max sampling rate & $2 \mathrm{~Hz}(4 \mathrm{~Hz}$ AST $)$ & $2 \mathrm{~Hz}$ \\
\hline Internal sampling rate & $4 \mathrm{~Hz}$ & $2 \mathrm{~Hz}$ \\
\hline \multicolumn{3}{|l|}{ Velocity Measurements } \\
\hline Range & $\pm 10 \mathrm{~m} / \mathrm{s}$ horizontal & $\pm 20 \mathrm{~m} / \mathrm{s}$ horizontal \\
\hline Accuracy & $\begin{array}{l}1 \% \text { of measured } \\
\text { value or } \pm 0.5 \mathrm{~cm} / \mathrm{s}\end{array}$ & $\begin{array}{l}0.25 \% \text { of } \\
\text { measured value } \\
\text { or } \pm 0.25 \mathrm{~cm} / \mathrm{s}\end{array}$ \\
\hline Doppler uncertainty & $\begin{array}{l}\text { Waves: } 3.5 \mathrm{~cm} / \mathrm{s} \\
\text { at } 1 \mathrm{~Hz} \text { for } 1 \mathrm{~m} \\
\text { cells }\end{array}$ & $\begin{array}{l}\text { One ping along } \\
\text { beam precision of } \\
5.4 \mathrm{~cm} / \mathrm{s} \mathrm{w} / 0.35 \\
\mathrm{~m} \text { bin }\end{array}$ \\
\hline \multicolumn{3}{|l|}{ Sensors } \\
\hline Flux-gate Compass & $\begin{array}{l}\text { Acc/res } 2 \% 0.1^{\circ} \text { for } \\
\text { tilts }<20^{\circ}\end{array}$ & Acc/res $2 \% 0.01^{\circ}$ \\
\hline $\begin{array}{r}\text { Piezoresistive } \\
\text { Pressure }\end{array}$ & $\begin{array}{l}\text { Range } 0-50 \mathrm{~m} ; \\
\text { Acc/res } 5 \mathrm{~cm} / \\
\leq 0.25 \mathrm{~cm}\end{array}$ & $\begin{array}{l}\text { Range } 0-20 \mathrm{~m} ; \\
\text { Acc/res } 5 \mathrm{~cm} / \\
\leq 0.05 \mathrm{~cm}\end{array}$ \\
\hline
\end{tabular}

The Waves feature of the RDI ADCPs determines wave height by one or more combinations of three measurement methods: velocities, surface tracking and bottom pressures. Measurements of wave orbital velocities, as well as pressures, are used to derive independent wave spectra, with correction for depth-dependent attenuation using linear wave theory. The surface tracking measurements are also used to determine a third version of the wave spectra. The primary wave spectra for the RDI ADCP is normally derived from doppler orbital velocities which are measured much closer to the surface, and therefore less affected by attenuation at high frequency than is the case for the bottom pressure sensor. For this study we computed wave spectra from both the velocities and surface tracking, to determine the non-directional wave parameters $\mathrm{H}_{\mathrm{s}}$ and $\mathrm{T}_{\mathrm{p}}$.

Note that the precision of the surface tracking for the RDI ADCP is approximately the bin size divided by 3.5 , or in the case of the intercomparison study, $0.1 \mathrm{~m}$, vs. the Nortek AWAC surface tracking precision that is about 0.01 $m$. The lesser precision of the RDI ADCP surface tracking, by comparison to the Nortek AWAC, is due to the use of longer pulse widths on each of its four beams, consistent with the need to measure the frequency shifts to determine Doppler velocities. In contrast, the AWAC uses a dedicated vertical beam which allows a very short acoustic pulse width to be employed.
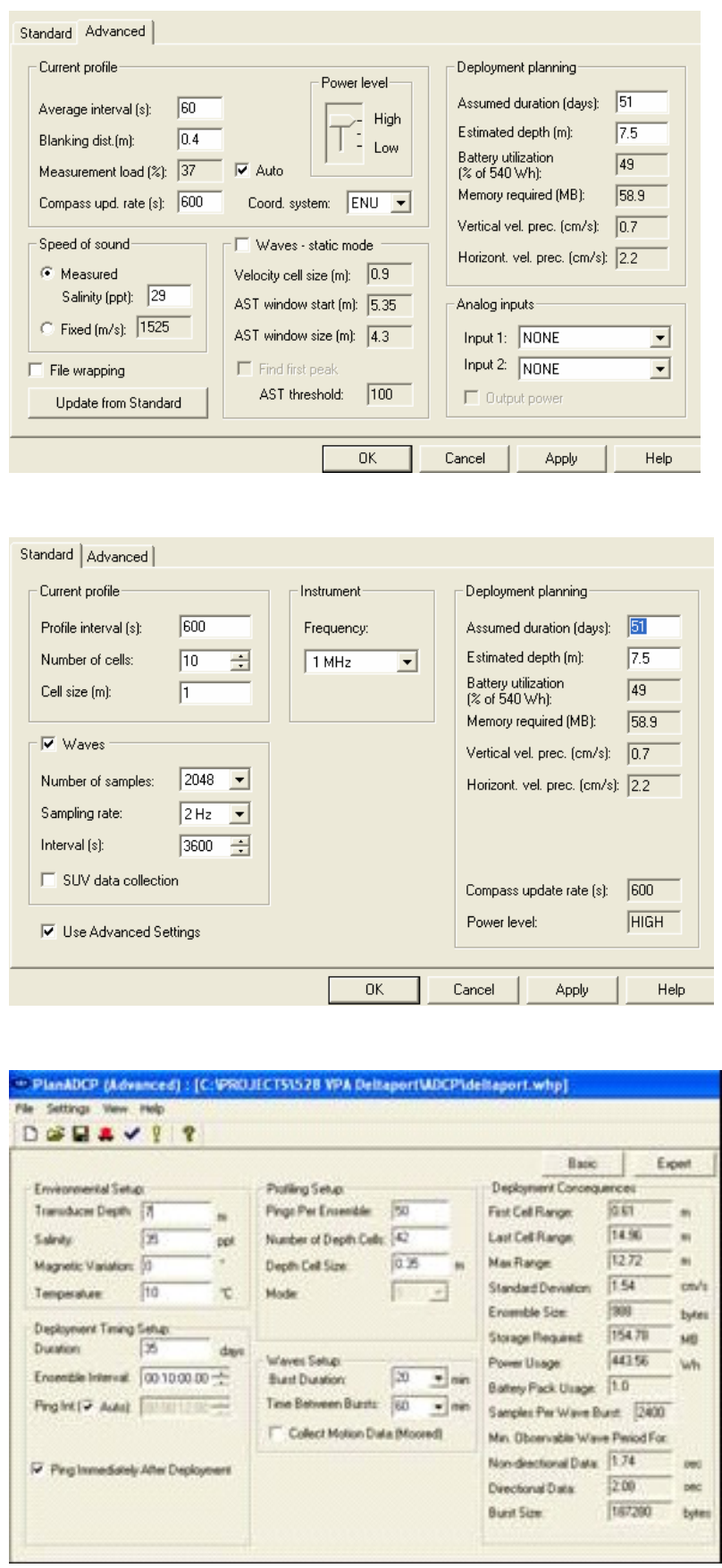

Fig. 4. Sampling parameters for the Nortek $1 \mathrm{MHz}$ AWAC (upper two panels), and for the RDI $1200 \mathrm{kHz}$ ADCP (lower panel). The AWAC AST samples at twice the velocity rate, or at $4 \mathrm{~Hz}$.

The RDI Sentinel Workhorse ADCP derives directional wave spectra from the orbital velocities. RDI uses a "wave array" algorithm [1] based on twelve (three or more from each beam) independent measurements of velocity that increases the resolution of the directional wave spectrum estimates. By comparison, the AWAC uses three measurements of velocity (one from each beam). Also, the RDI ADCP uses the Broadband acoustic pulse signal processing technique [5], which effectively increases the precision of the measured velocities. 


\section{Sampling Parameters}

The AWAC recorded 17-minute wave bursts and the RDI ADCP 20 minutes. Only 17 minutes of the ADCP data were used for spectral analyses. The AWAC bursts began on the hour and the ADCP on the half hour. Overlap in sampling was avoided to eliminate any possibility of acoustic interference or "cross talk" if the two instruments were operated simultaneously. The non-directional wave spectra parameter data from each instrument were interpolated to a common hourly increment on 15 minutes after the hour, mid-way between the measurement time of the Nortek AWAC (on the hour) and RDI ADCP (on the half-hour). All wave direction data are reported in degrees magnetic.

The set-up parameters used for the AWAC and ADCP are shown in Fig. 4.

\section{Wave Results - Spectral Parameters $\left(H_{s}, T_{p}\right)$}

For both the AWAC and ADCP, the wave spectra are computed and the wave parameters are derived as: significant wave height $\left(\mathrm{H}_{\mathrm{s}}\right)$ equal to four times the square root of the integrated spectra. The peak period $\left(T_{p}\right)$ is the centre frequency of the spectral band with the most energy. Because the AWAC measurements are also available as a time series of wave height, the additional parameters $\mathrm{H}_{\max }$, $\mathrm{H}_{1 / 10}, \mathrm{H}_{1 / 3}$ and $\mathrm{T}_{\text {mean }}$ are readily determined using the zero-upcrossing method in the time domain. The RDI ADCP can also provide a time series representation of surface tracking, although the precision is reduced as discussed above.

Waves during the 13 April - 3 June 2004 data collection period were generally $0.2-0.4 \mathrm{~m}$ in height, increasing to almost $2 \mathrm{~m}$ during a northwesterly storm on 27-28 April (Fig. 5). A cutoff of $\mathrm{H}_{\mathrm{s}}=0.3 \mathrm{~m}$ has been used to reduce the scatter at small wave heights. Wave periods are small, generally 6 seconds or less. The wave directions (from) were largely confined to northwest/southeast by the orientation of the Strait and by the two dominant wind directions.
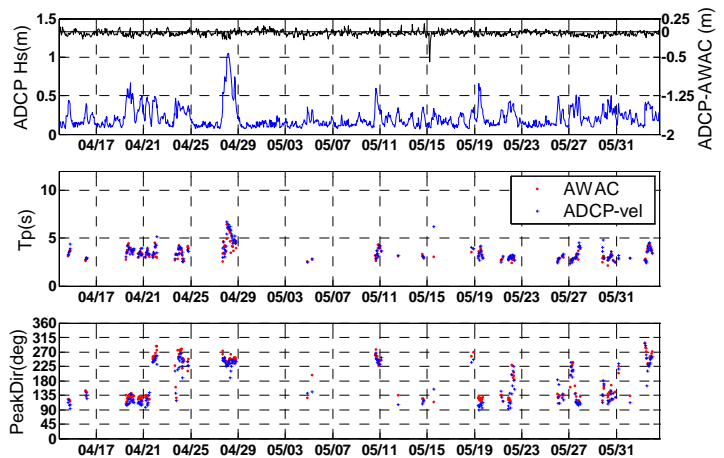

Fig 5. Comparison of the wave parameter time series from the AWAC and RDI ADCP (Red=AWAC [surface track]; Blue=RDI $A D C P$ [velocity-derived]); $H_{s}, T_{p}$, Peak Dir (for $H_{s}>0.3 m$ ). The black line in the upper panel represents the difference in $\mathrm{H}_{\mathrm{s}}$ of the RDI ADCP less the AWAC (see special scale on the right).

\section{Comparison of Wave Heights}

Fig. 6a,b compare the significant wave heights from the two instruments, based on the moderate to larger waves, i.e. $H_{s} \geq 0.3 \mathrm{~m}$, amounting to a total of approximately 200 one-hourly samples. The regression is very good with $R^{2}$ values of 0.93 and 0.91 . In the case of the AWAC surface-tracking versus RDI ADCP velocity-derived values, the AWAC tended to produce $\mathrm{H}_{\mathrm{s}}$ values slightly larger ( $0.05 \mathrm{~m}$ ) than the RDI ADCP.

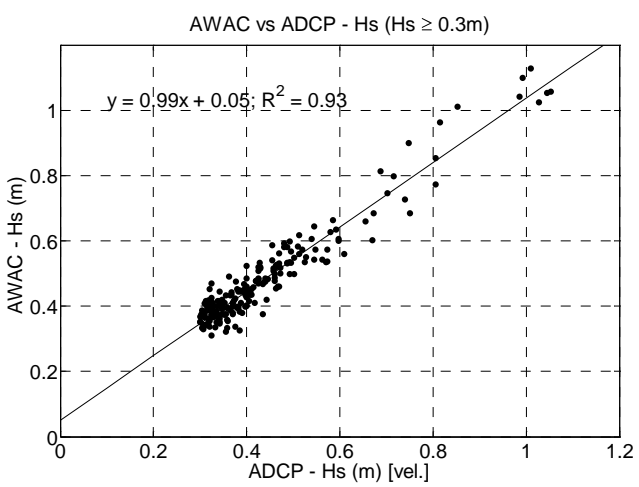

Fig. 6a Scatter plot of $\mathrm{H}_{\mathrm{s}} ;\left(\mathrm{H}_{\mathrm{s}}>0.3 \mathrm{~m}\right)$; AWAC [surface track] versus ADCP [velocity-derived]. $\mathrm{Y}=0.99 \mathrm{X}+0.05 \quad \mathrm{R}^{2}=0.93$

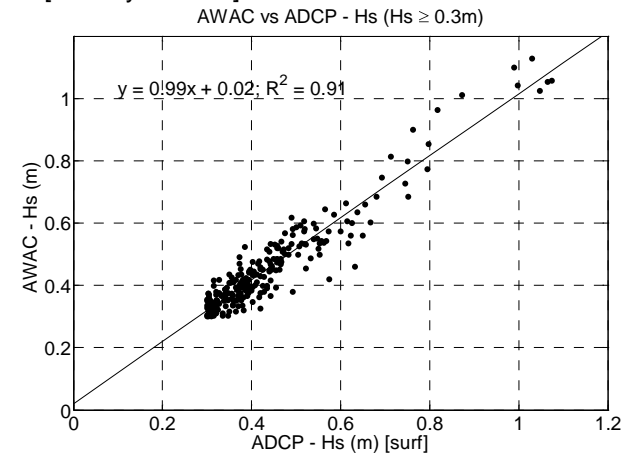

Fig. 6b. AWAC $\mathrm{H}_{\mathrm{s}}$ [surface track] versus $A D C P \mathrm{H}_{\mathrm{s}}$ [surface track] for $\mathrm{H}_{\mathrm{s}}>0.3 \mathrm{~m}$. $\mathrm{Y}=0.99 \mathrm{X}+0.02 \quad \mathrm{R}^{2}=0.91$.

For this comparison of $\mathrm{H}_{\mathrm{s}}, \mathrm{RDI}$ ADCP values were computed to an upper frequency limit of $0.5 \mathrm{~Hz}$ while the upper frequency limit, used for the AWAC computation, was $1 \mathrm{~Hz}$ (very little energy was present in the autospectra from 1 to $2 \mathrm{~Hz}$ ). A similar regression analysis for the RDI ADCP surface tracking- (over frequencies of up to nearly 1 $\mathrm{Hz}$ ) vs. velocity-derived $\mathrm{H}_{\mathrm{s}}$ results in a mean difference of $0.04 \mathrm{~m}$. In Fig. 6b, we compare the $\mathrm{H}_{\mathrm{s}}$ values computed from surface tracking on both the AWAC and the RDI ADCP (now with an upper frequency limit of nearly $1 \mathrm{~Hz}$ ). In this case, the difference between the AWAC and RDI ADCP $\mathrm{H}_{s}$ values is reduced to only $0.02 \mathrm{~m}$. While this difference in $\mathrm{H}_{\mathrm{s}}$ is very small, we note that a higher positive noise floor in the AWAC wave spectra (Fig. 9 and 10 ), relative to that of the RDI ADCP, has approximately the correct magnitude to account for this small difference.

\section{Comparison of Wave Periods}

A similar regression was performed for the peak periods from the two instruments (Fig. 7a,b), again in cases where $\mathrm{H}_{\mathrm{s}} \geq 0.3 \mathrm{~m}$. As one would expect, there is more scatter $\left(R^{2}=0.65-0.7\right)$ among the peak periods from the AWAC and ADCP due to the nature of this particular spectral parameter, especially at longer periods where the effective spectral resolution is reduced. 


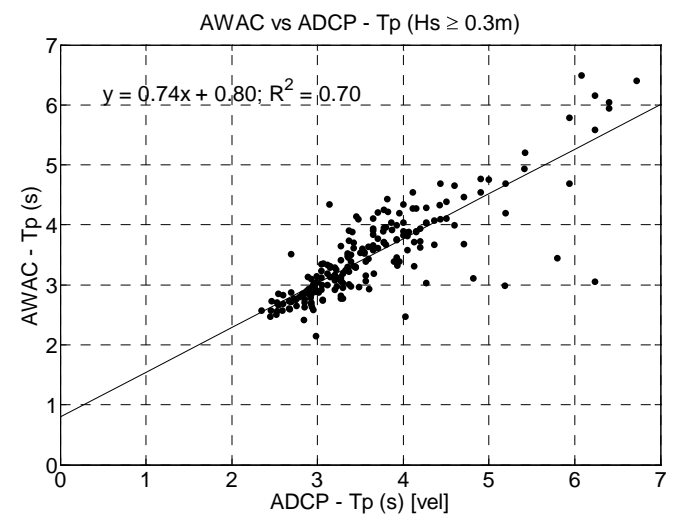

Fig. 7a. AWAC $T_{p}$ [surface track] versus ADCP $T_{p}$ [velocity] for $\mathrm{H}_{\mathrm{s}}>0.3 \mathrm{~m} . \quad \mathrm{R}^{2}=0.70$

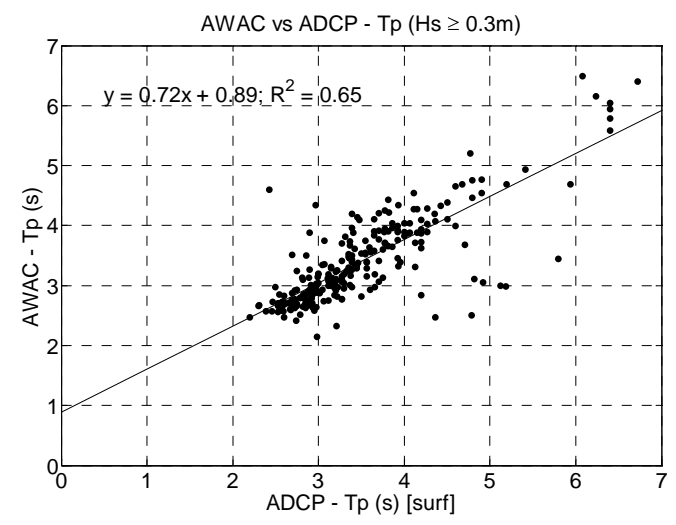

Fig. 7b. AWAC $T_{p}$ [surface track] versus $A D C P T_{p}$ [surface track] for $\mathrm{H}_{\mathrm{s}}>0.3 \mathrm{~m} . \quad \mathrm{R}^{2}=0.65$

Overall, the scatter plot approximately tracks a 1:1 relationship; however, the regression fit deviates from this due to 5 pairs of values where the AWAC $T_{p}$ lies in the 2.5-3.5 s range, while the ADCP values are approximately 5-7 seconds period range. The wave auto-spectra for these 5 sets of values were examined (from the RDI ADCP software) in detail, as were 4 cases of large deviations in $T_{p}$, selected from similar comparisons (not shown) of $T_{p}$ values derived from the RDI ADCP surface tracking- and velocity-derived wave spectra. For all of these auto-spectra, two distinct spectral peaks occurred, one at a higher frequency and the other at a lower frequency of 4.5 to 6.5 second periods. In the case of the RDI ADCP derived values, the peak period was observed to change abruptly from the low to the high frequency peak, or vice versa, over time scales as short as one hour. In the case of the Nortek AWAC, the selected peak period was always the high frequency or low peak period value. Although the wave spectra were similar, the preferential tendency of the AWAC to exhibit comparatively larger spectral densities at higher frequencies may reflect a larger degree of smoothing which is apparently applied in the Nortek software over that used in the RDI software (see Fig. 8, 9 and 10 below), which is discussed further below. In any case, an examination of the full wave auto-spectra provides a much more complete assessment of the frequencies (or periods) at which appreciable energy is present, whereas the single value of $T_{p}$ can be misleading.

\section{E. Wave Results - Non-Directional Wave Spectra}

Wave height spectra from the AWAC and RDI ADCP are compared for small $\left(\mathrm{H}_{\mathrm{s}}=0.3 \mathrm{~m}\right)$, moderate $\left(\mathrm{H}_{\mathrm{s}}=0.8 \mathrm{~m}\right)$, and large $\left(\mathrm{H}_{\mathrm{s}}=1.1 \mathrm{~m}\right)$ waves. In all cases the AWAC spectra are based on the surface track, whereas the ADCP plots show the spectra from the pressure (red), orbital velocities (green), and the surface track (blue). The RDI ADCP computed $\mathrm{H}_{s}, \mathrm{~T}_{\mathrm{p}}$ parameters, for both velocity- and surface-track derivations, are shown in the figure captions. The spectral resolution for the RDI ADCP is $0.016(1 / 64) \mathrm{Hz}$ while the Nortek AWAC has a spectral resolution of $0.01 \mathrm{~Hz}$.

The spectrum from the pressure sensor does not include energy above $0.29 \mathrm{~Hz}$ ( $3.4 \mathrm{sec}$ period) and, if used, would underestimate significant wave heights. The ADCP surface track spectra (blue) extend to $0.94 \mathrm{~Hz}$ (1 $\mathrm{sec})$. An orbital velocity spectra cut off at $0.5 \mathrm{~Hz}(2 \mathrm{sec})$ was used as a best upper frequency limit for the majority of bursts. (Note: Agreement between the surface tracking and velocity spectra for the RDI ADCP was found out to higher frequencies approaching $1 \mathrm{~Hz}$ for the moderate and larger wave spectra, but for the small wave case, going beyond the $0.5 \mathrm{~Hz}$ cut-off would result in noise dominating signal in the auto-spectral values.)

The AWAC spectra based on the surface track was cut-off at $1 \mathrm{~Hz}$, although the $4 \mathrm{~Hz}$ sampling rate of the AWAC AST actually provides spectral information out to 2 $\mathrm{Hz}$, since there is little wave energy beyond $1 \mathrm{~Hz}$.

\section{Small Waves}

For small waves $\left(\mathrm{H}_{\mathrm{s}} \sim 0.3 \mathrm{~m}, \mathrm{~T}_{\mathrm{p}} \sim 2.6 \mathrm{sec}\right)$ the energy in the AWAC wave spectra (Fig. 8b) is centered at $0.38 \mathrm{~Hz}$ $\left(T_{p}=2.62 \mathrm{sec}\right)$ and the integration resulted in a significant wave height of $0.31 \mathrm{~m}$.

The surface track from the RDI ADCP (Fig. 8a) is most similar to the AWAC spectra. The $\mathrm{H}_{s}$ and $\mathrm{T}_{\mathrm{p}}$ parameters computed from both the velocity- and surface-track derived ADCP spectra, in this one case, agree well with those from the AWAC, even though the ADCP velocity-derived spectra are cut off at $0.5 \mathrm{~Hz}$. As is the case in comparisons of spectral parameters though-out this study, the AWAC and RDI ADCP measurements were separated in time by 30 minutes, so individual comparisons can reflect time varying changes in this highly fetch- and duration-limited wave generation regime.

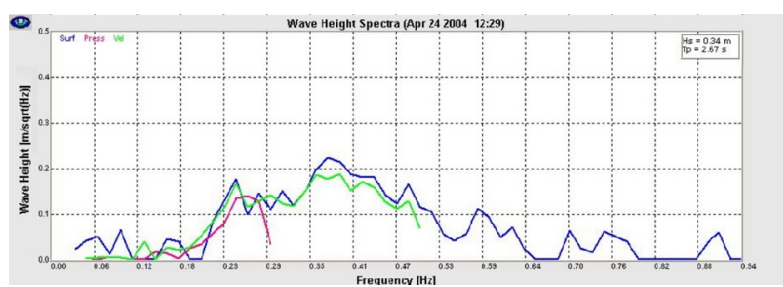

Fig. 8a. ADCP Energy Spectra for small waves; April 24 12:29 $\mathrm{Hs}=0.28 \mathrm{~m}, \mathrm{~T}_{\mathrm{p}}=2.56 \mathrm{~s}$ [velocity], $\mathrm{H}_{\mathrm{s}}=0.34 \mathrm{~m}, \mathrm{~T}_{\mathrm{p}}=2.67 \mathrm{~s}$ [surface track] 


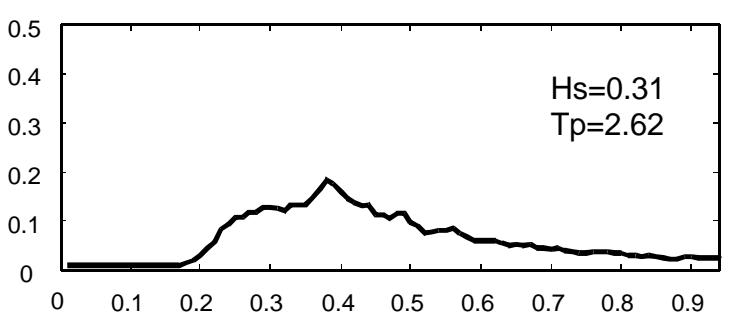

Fig. 8b. AWAC Energy Spectra for small waves, April 24 12:00 $H_{s}=0.31 \mathrm{~m}, \mathrm{~T}_{\mathrm{p}}=2.62 \mathrm{~s}$

\section{Moderate Waves}

For moderate waves $\left(\mathrm{H}_{\mathrm{s}} \sim 0.8 \mathrm{~m}, \mathrm{~T}_{\mathrm{p}} \sim 5.7 \mathrm{sec}\right)$ the energy in the AWAC wave spectra (Fig. 9b) is centered at $0.18 \mathrm{~Hz}\left(T_{p}=5.66 \mathrm{sec}\right)$ and the integration of spectral densities resulted in a significant wave height of $0.88 \mathrm{~m}$. A secondary peak occurred at about $0.26 \mathrm{~Hz}(3.8 \mathrm{sec}$ period). The noise floor of the AWAC spectra is higher than for the small waves.

The pressure sensor captures the wave energy at lower frequencies; however there still remains significant energy at higher frequencies that is not measured. Both the RDI ADCP velocity- and surface-derived spectra look good, and are in good agreement with that of the AWAC.

\section{Large Waves}

For the largest wave event in the record $\left(\mathrm{H}_{\mathrm{s}} \sim 1.1 \mathrm{~m}\right.$, $\mathrm{T}_{\mathrm{p}} \sim 6.3 \mathrm{sec}$ ) the AWAC wave spectra (Fig. 10b) shows three wave sets of different frequency $(0.16,0.2$ and 0.26 $\mathrm{Hz}$ ). The lowest frequency peak was largest and resulted in the peak period of 6.25 seconds. The integration for determination of $\mathrm{H}_{\mathrm{s}}$ produced a value of $1.07 \mathrm{~m}$.

The wave energy plot from the RDI ADCP (Fig. 10a) also has three peaks, but the first and largest peak has more energy than the other two, and more than the main AWAC peak. The computation of $\mathrm{H}_{\mathrm{s}}$ however, results in a similar value to the AWAC (1.08 versus $1.07 \mathrm{~m})$. The velocity- and pressure-based RDI ADCP spectra agree well with the surface-track values, out to their cutoff frequencies.

This three-peak energy spectrum was transient, and did not show up in the 02:30 ADCP burst, nor the 04:00 AWAC burst. This suggests that the wave field had not reached a steady state.

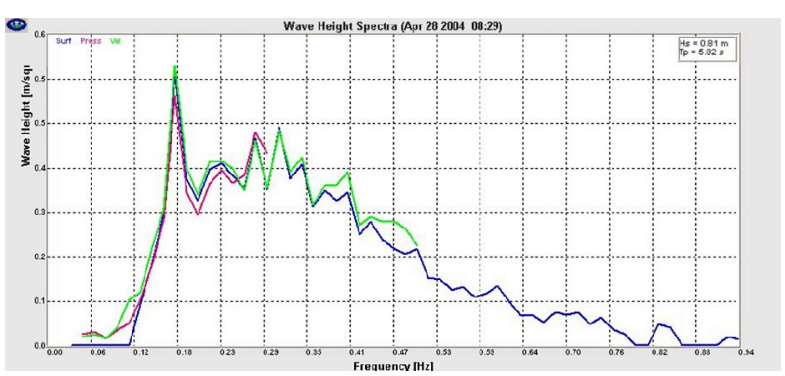

Fig. 9a. ADCP Energy Spectra for moderate waves April 28 08:29. $\mathrm{H}_{\mathrm{s}}=0.82 \mathrm{~m}, \mathrm{~T}_{\mathrm{p}}=5.8 \mathrm{~s}$ [velocity]; $\mathrm{H}_{\mathrm{s}}=0.81 \mathrm{~m}, \mathrm{~T}_{\mathrm{p}}=5.8 \mathrm{~s}$ [surface track]

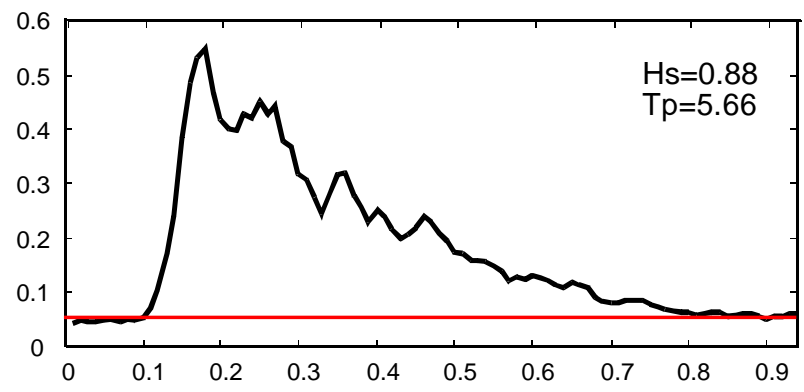

Noise floor

Fig. 9b. AWAC Energy Spectra for moderate waves, April 28 08:00 $H_{s}=0.88 \mathrm{~m} \mathrm{~T}_{\mathrm{p}}=5.66 \mathrm{~s}$

The spectral levels at the very lowest and highest frequencies are very close to zero values in the RDI wave spectra, while the corresponding Nortek spectral values approach constant, but notably non-zero values. The size of the non-zero noise "floor" appears to be dependent on the overall wave spectral activity, as it is also apparent in the moderate wave spectra but it is nearly indiscernible in the small wave spectra case (Fig. 8).

Also of interest is the much more distinct spectral peaks exhibited in the RDI ADCP wave spectra as compared to the Nortek spectra, which is especially apparent for the largest waves. This likely reflects the degree of spectral smoothing applied in computing the wave auto-spectra, which apparently is considerably greater for the Nortek-derived spectra than for the RDI-derived spectra. In general terms, more distinct spectral peaks are preferable if they are consistent and repeatable.

\section{F. Wave Results - Directional Wave Spectra}

Wave directions are derived from the orbital velocities measured in near-surface bins. In the case of the RDI ADCP, the three uppermost available $0.35 \mathrm{~m}$ high bins relative to the water surface, were used for each of four beam directions, In the case of the Nortek AWAC a single near-surface bin in each of three beams was used. Cross spectra of the orbital velocity array measurements are used to determine the directional wave spectra. Both the manufacturers (Nortek AWAC and RDI ADCP) use the Maximum Likelihood Method (MLM) to determine the wave direction at each frequency, based on three iterations. As noted above, the much larger total number of independent velocity measurements in the ADCP wave array (12 vs. 3 for the Nortek AWAC) results in an increase in the degrees of freedom in the spectral analysis, and a corresponding increase in the reliability of the directional spectrum estimation. 


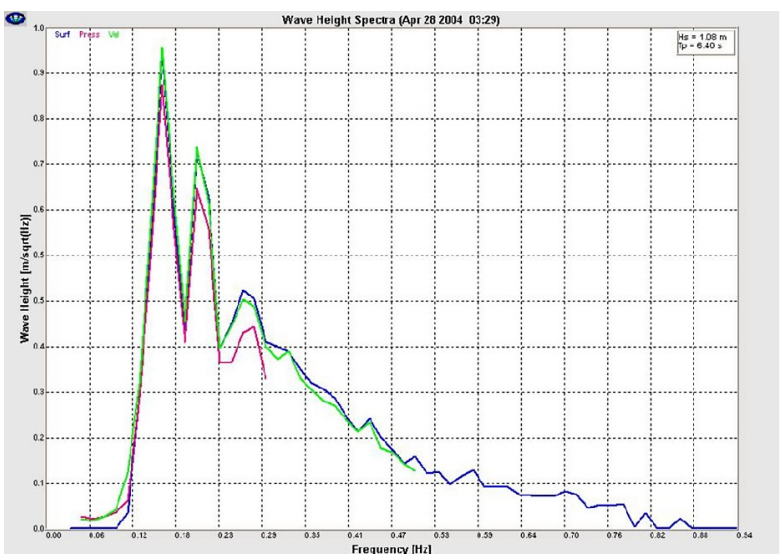

Fig. 10a. ADCP Energy Spectra for the largest waves April 28 03:29. $\mathrm{H}_{\mathrm{s}}=1.08 \mathrm{~m}, \mathrm{~T}_{\mathrm{p}}=6.4 \mathrm{~s}$ [velocity], $\mathrm{H}_{\mathrm{s}}=1.08 \mathrm{~m}, \mathrm{~T}_{\mathrm{p}}=6.4 \mathrm{~s}$ [surface track]

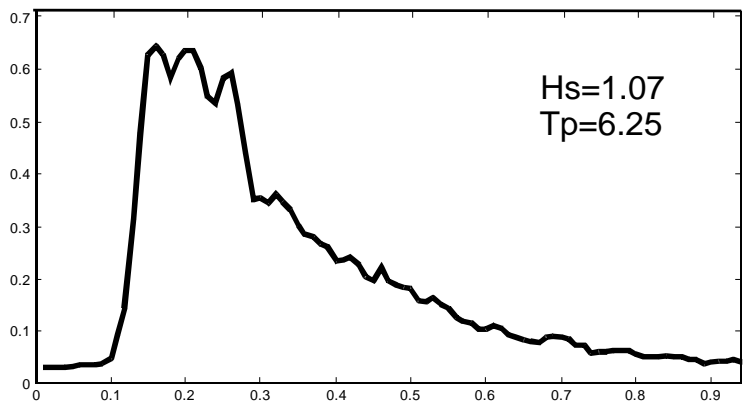

Fig. 10b. AWAC Energy Spectra from AWAC, for the largest waves April 28 03:00. $H_{s}=1.07 m, T_{p}=6.25 \mathrm{~s}$

Because both the Strait of Georgia and the predominant wind directions are aligned northwest/southeast, the largest waves also tend to come from one of these two directions. This is evident in the bi-modal character of the wave direction time series presented in Fig. 5 (for $\mathrm{H}_{\mathrm{s}}>0.3 \mathrm{~m}$ ). Both the AWAC and the RDI ADCP show similar overall wave directions.

A comparative scatter plot of the computed peak and mean wave directions, for $\mathrm{H}_{\mathrm{s}}>0.3 \mathrm{~m}$, is presented in Fig. $11 a, b$.

The peak wave direction represents the direction corresponding to the peak period. The mean wave direction (MWD) is a weighted average of all directions in the spectrum. This can be misleading if there are wave sets from different directions. In all cases the wave directions are reported as direction from which the wave is traveling, and they are in degrees magnetic.

The peak directions compare fairly well $(y=0.96 x+19.4$; $\left.R^{2}=0.91\right)$ although the AWAC wave directions are about $15-20^{\circ}$ greater than those from the RDI ADCP for the southeasterly waves, and about $9^{\circ}$ greater for the westerly waves. The comparison of mean wave directions (Fig. $11 \mathrm{~b}$ ) is even better, agreeing to within $10^{\circ}$ for both the main wave directions, $\quad\left(y=1.03 x+4.4 ; R^{2}=0.98\right)$.

Because of the spatial array of wave orbital velocity measurements obtained by both instruments, it is possible to resolve the frequency and direction of multiple sets of waves.

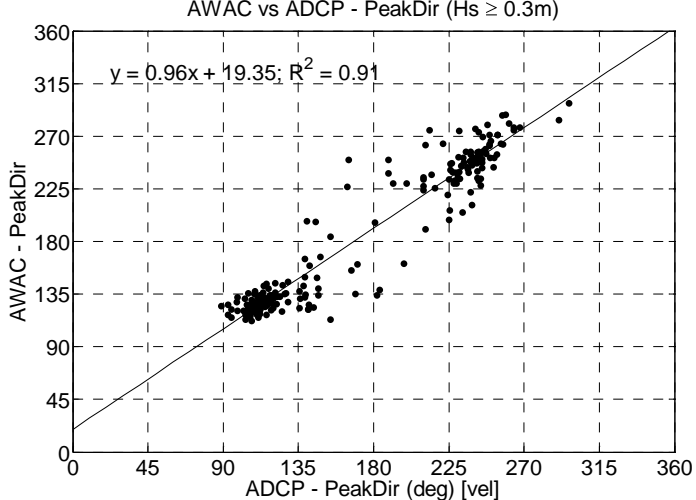

Fig. 11a. Comparison of the peak wave directions from the AWAC and ADCP, for $\mathrm{H}_{\mathrm{s}}>0.3 \mathrm{~m} . \quad \mathrm{Y}=0.96 \mathrm{X}+19.4 \mathrm{R}^{2}=0.91$

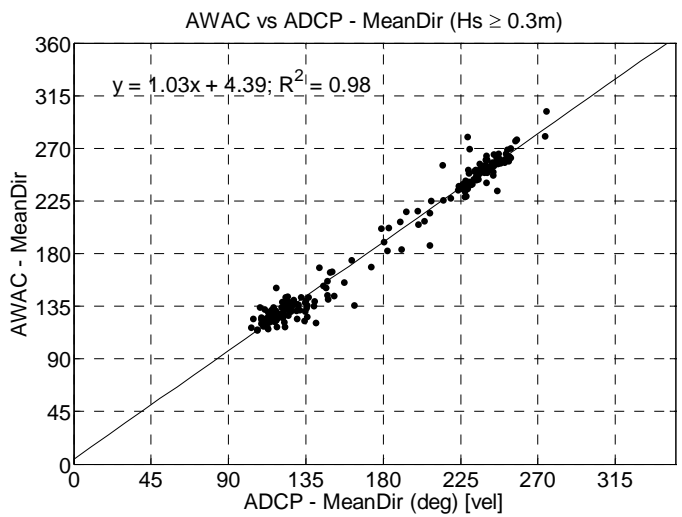

Fig. 11b. Comparison of the mean wave directions from the AWAC and ADCP, for $\mathrm{H}_{\mathrm{s}}>0.3 \mathrm{~m} . \quad \mathrm{Y}=1.03 \mathrm{X}+4.4 \mathrm{R}^{2}=0.98$

Polar plots of the directional wave spectra are presented for both the AWAC and ADCP for the moderate (Fig. 12) and large (Fig. 13) wave events previously discussed.

For the moderate wave event of Apr 28 07:30/08:00 both the AWAC and the RDI ADCP show a dominant wave set with a minor secondary set at higher frequency (Fig. 12a,b). The direction of the higher frequency secondary wave set is rotated about $10^{\circ}$ in both cases. The directional spreading of the wave spectra is less for the RDI ADCP than the AWAC

For the large wave event, three distinct wave sets are evident in both the AWAC and ADCP polar plots (Fig. $13 a, b)$. These three wave sets are also evident in the previously presented auto-spectra plots (Fig. 10a,b). However this wave pattern appeared to be transient since it was not evident in wave spectra from adjacent wave bursts. The ADCP appears to have higher energy levels than the AWAC, however total energy levels are similar as evidenced by the similarity in the computed $\mathrm{H}_{\mathrm{s}}$ values.

In order to quantify the amount of directional spreading computed by each instrument, we present the wave energy at the peak period, versus wave direction, every three hours during the storm period 01:30-07:30 April 28 (Fig. 14). During this time the RDI ADCP wave direction peaks were much better resolved than those from the AWAC, as might be expected given the array of 12 velocity values of the RDI ADCP vs. only 3 from the Nortek AWAC. 


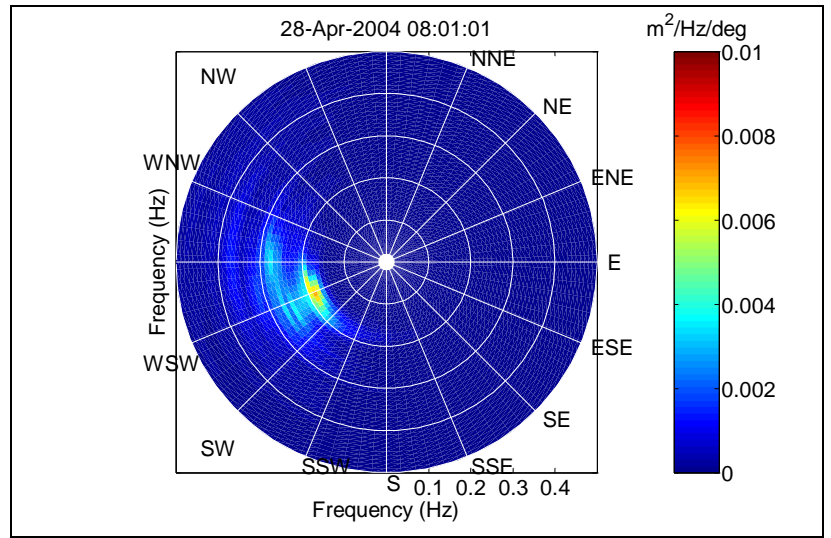

Fig. 12a. Directional Wave Spectra from AWAC for moderate wave event April 28 08:00 $\left(\mathrm{H}_{\mathrm{s}}=0.88 \mathrm{~m} \mathrm{~T}_{\mathrm{p}}=5.66 \mathrm{~s}\right)$.

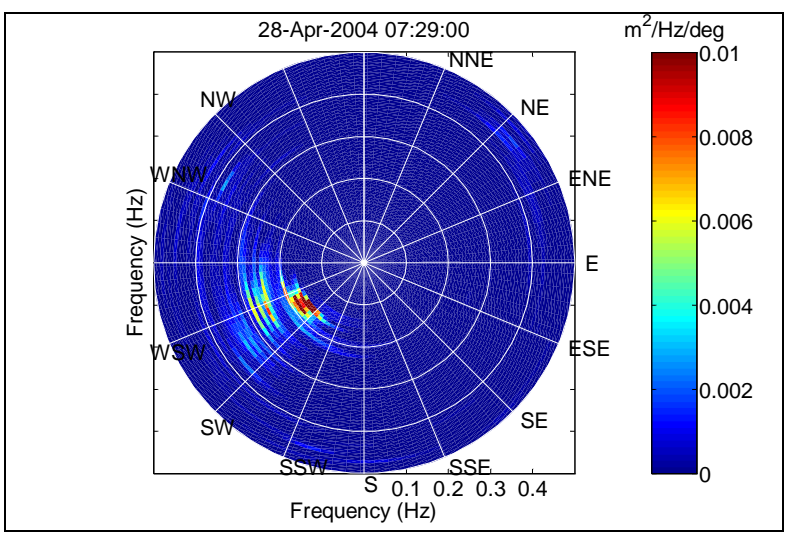

Fig. 12b. Directional Wave Spectra from the ADCP for the moderate wave event April 28 07:29 $\mathrm{H}_{\mathrm{s}}=0.76 \mathrm{~m}, \mathrm{~T}_{\mathrm{p}}=6.4 \mathrm{~s}$ [velocity] $H_{s}=0.76 \mathrm{~m}, T_{p}=6.4 \mathrm{~s}$ [surface track]. The spectral resolution for the RDI ADCP is $0.008 \mathrm{~Hz}$.

The directional span between the half-peak power levels of the directional spectral peak for the RDI ADCP is 10-30 degrees vs. 20-55 degrees or more for the Nortek AWAC (see Fig. 15 for the 6.25/6.4 s wave band; directional spectral peaks were also examined for the 5.3 $\mathrm{s}$ wave band - not shown). Moreover, the RDI ADCP directional spectral peak tends to be very nearly symmetrical while a considerable degree of asymmetry is evident in the directional spectra for the AWAC. This difference in symmetry for these particular hourly samples may explain the overall better agreement between mean wave direction, over that of peak wave direction, for the Nortek AWAC and the RDI ADCP as seen in Fig. 11.

The large wave event of April 27-28 was generated by atmospheric pressure gradients due to a $1000 \mathrm{mb}$ low pressure system located on the continent, and a $1030 \mathrm{mb}$ high pressure system offshore. The pressure contours (isobars) were aligned northwest/southeast, the same as the direction of the Strait of Georgia, resulting in maximum fetch for the wind. Late of the $27^{\text {th }}$ the wind was from the west-northwest increasing in speed to 30 knots, gusting to 40 knots. On the $28^{\text {th }}$ the winds reduced in magnitude and became more westerly. The wave parameters measured by the AWAC and RDI ADCP were $\mathrm{H}_{\mathrm{s}}=1.07$ (both) and $T_{p}=6.25 \mathrm{~s}(6.4 \mathrm{~s}$ for the RDI ADCP), with transient higher frequency wave sets as well at about 4 and 5 second period.

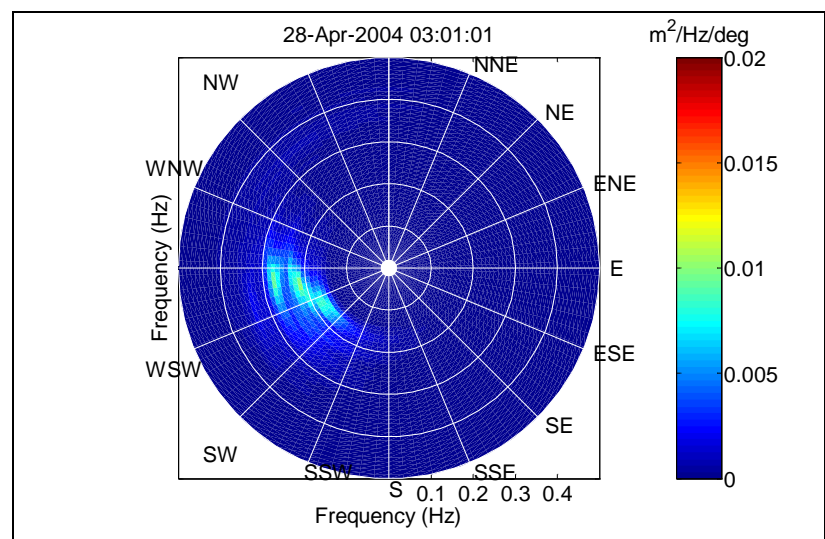

Fig. 13a. Directional Wave Spectra from the AWAC for the large wave event April 28 03:00 $\quad H_{s}=1.07 \mathrm{~m}, \mathrm{~T}_{\mathrm{p}}=6.25 \mathrm{~s}$

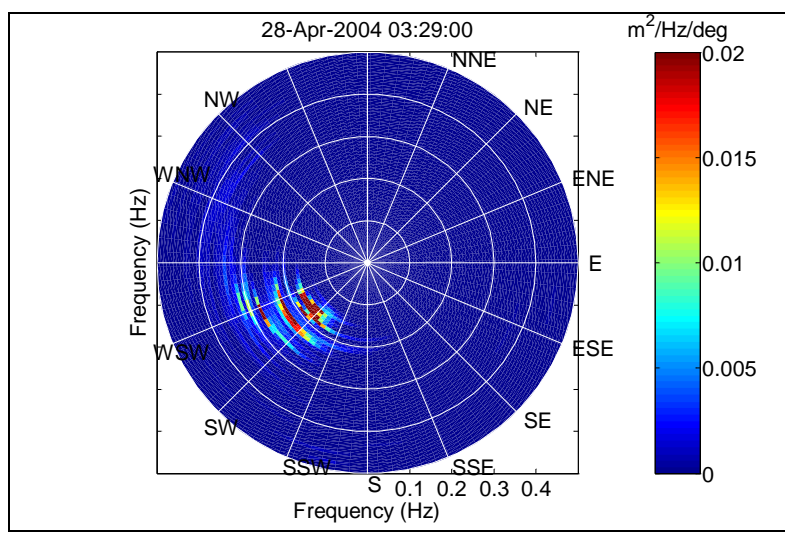

Fig. 13b. Directional Wave Spectra from the ADCP for the large wave event, April $2803: 29 \mathrm{Hs}=1.06 \mathrm{~m}, \mathrm{~T}_{p}=6.40 \mathrm{~s}$ [velocity]; $\mathrm{H}_{\mathrm{s}}=1.08 \mathrm{~m}, \mathrm{~T}_{\mathrm{p}}=6.40 \mathrm{~s}$ [surface track]

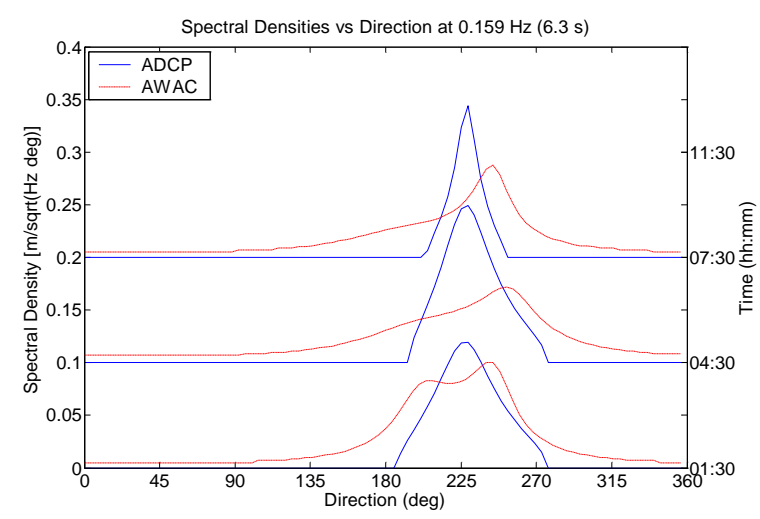

Fig. 14. Stack plot of spectral density versus direction at $6.3 \mathrm{sec}$, every 3 hours (01:30, 04:30 and 07:30 on April 28). Note the offset in the individual spectral density lines by $0.1 \mathrm{~m} / \mathrm{sqrt}(\mathrm{Hz} \mathrm{deg})$. The spectral resolution for the RDI ADCP is $0.008 \mathrm{~Hz}$.

The change in direction of the lower frequency waves relative to those at higher frequencies can be explained by wave refraction. Refraction would tend to reduce the wave directions as they rotate counter-clockwise to try to align across the sloping bathymetry at the edge of the Bank (see Fig. 2). The longer period waves will refract, i.e. rotate counter-clockwise, to a greater degree, since these longer waves have greater vertical scales and 
interact with the bottom in deeper water depths than for the higher frequency waves. Wave refraction accounts for larger turning, and lower directional values of the low frequency relative to the higher frequency waves as is evident in both the AWAC and RDI ADCP directional wave spectra (Fig. 13). Interestingly, the RDI ADCP measured directional wave spectra at the lowest frequency peak exhibit a greater degree of turning, and apparent refraction with magnetic directions of about 235 degrees vs. the corresponding Nortek peak directions, which are 15 to 30 degrees larger (more from the west rather than southwest). This difference may be indicative of a better directional measurement capability for the RDI ADCP.

\section{G. Surface Tracking}

Unlike the RDI ADCP, the AWAC vertical beam sonar is optimized for surface tracking. Using a narrow beam, short pulse, and high frequency $4 \mathrm{~Hz}$ sampling, the AWAC provided a high quality time series of the wave heights. Within the time series bursts there were frequent occurrences of well-defined boat wakes, understandable given the proximity of the mooring to two terminals and the port of Vancouver.

This sensitivity of the surface tracking to boat wakes is a reminder that the AWAC surface tracking will have a larger response to surface phenomena, if present, in addition to wind-generated ocean waves than is the case for the pressure sensors. The velocity wave sensor array will also be more sensitive to non-wave surface processes, albeit somewhat reduced at the very highest frequencies from that of surface tracking. If boat wakes are large enough, they should be detected and removed from the wave spectral results, although we believe this is not the case in the present data set, as the largest boat wakes and wash are limited to no more than $0.3 \mathrm{~m}$ and are of very short duration (typically less than one minute per event). Near-surface bubbles due to breaking waves or intense wind-over-water events will also be preferentially detected by the surface tracking $[4,6]$ over the actual surface ocean waves. However, for the present data set, the winds were nearly always light or moderate, with the most notable exception being the 27-28 April storm, and there is no definitive evidence in the data of bubbles causing any appreciable data losses in the AWAC surface tracking values.

The AWAC wave height time series also clearly illustrated the non-linearity of the waves during the April 27-28 storm (Fig. 15). The pressure sensor (red curve) does not fully capture the wave heights because of the attenuation and smoothing that result from the sensor being located at $7 \mathrm{~m}$ depth. The interpolated portion of the Nortek AST record (at $t=997 \mathrm{sec}$ ) is due to rejection of actual surface measurements as false targets, such as bubbles. However, after examination by the manufacturer of this data segment, we are advised that the interpolated data points are due to "the rejection of large values caused by a transient wake event".

For this episode of large waves as shown in Figure 15, in the data ensemble of 30 minutes later starting at 0730 , the RDI ADCP data sets were examined to determine how the surface waves were represented by its surface tracking and velocity sensors. As expected, the four surface tracking time series values of the RDI ADCP are noisier, but also show similar features in the form of ragged wave patterns, i.e. as departures from regular sinusoidal wave behavior. The radial velocities measured on the four RDI ADCP beams in the uppermost bins also exhibit similar ragged wave patterns, but without any notable dropouts in the individual $2 \mathrm{~Hz}$ data points.

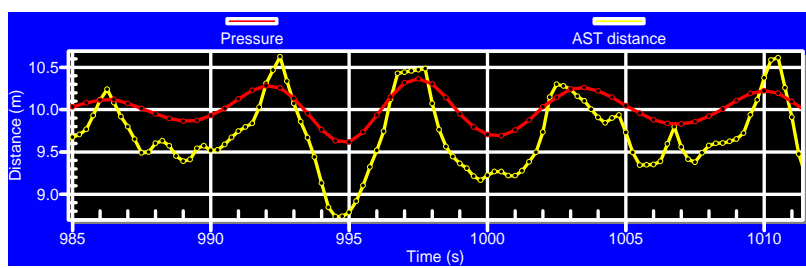

Fig. 15. AWAC time series of large waves during April 28 07:00 burst.

\section{DEEPER WATER EQUATORIAL DIRECTIONAL WAVE MEASUREMENTS}

From late 2002 to the present, RDI $600 \mathrm{kHz}$ directional wave ADCPs have been used in 20 to $25 \mathrm{~m}$ water depth for measurements of waves in the Gulf of Guinea in West Africa. In these equatorial coastal waters, waves result: (a) from high latitude extra tropical storms in the Southern Ocean which occur as very long period swell waves in the West African region, and (b) due to short duration wind squall events. While the magnitude of the waves are comparatively low, usually about $1-2 \mathrm{~m}$ in terms of $\mathrm{H}_{\mathrm{s}}$ in deeper waters and about one-half this amplitude in shallow coastal waters, the long period swell events are of concern for the operation and berthing of some large vessels.

Measurement of the wave directions of comparatively small, very long period waves is a challenging issue for wave instruments. Wave buoys have reduced responses to long period waves. By using large bin sizes of $2 \mathrm{~m}$, and collecting continuous measurements over periods of 60 to 90 minutes, the ADCP directional wave instrument has proven to be capable of providing usable directional and non-directional wave spectra for periods of up to 20-26 seconds. For the comparatively little swell energy that occurs beyond periods of 26 seconds, the pressure sensor has provided non-directional wave spectra out to periods of 40 seconds. In water depths of $20-25 \mathrm{~m}$, the highest resolvable frequencies using velocity-derived wave spectra were found to be $0.28 \mathrm{~Hz}$ corresponding to a 3.6 second wave period.

A wave sampling program of this type in a remote area, where logistics costs are high, leads to the need for long term instrument deployments of typically three months. The long duration of measurements, combined with the high duty cycle to obtain adequate data to resolve very long period waves, necessitated the use of considerable amounts of internal data storage (880 Mbytes) and an array of five individual alkaline battery packs, which the RDI ADCP can be equipped with.

\section{SUMMARY AND CONCLUSIONS}

From an intercomparison of the RDI Directional Wave Array ADCP and the Nortek AWAC instruments, as carried out in $7 \mathrm{~m}$ water depth, we conclude that:

(1) The AWAC surface track is more precise than the ADCP surface track because of the dedicated narrow vertical beam which has a short acoustic pulse, and is sampled at $4 \mathrm{~Hz}$. However, in this study the ADCP 
surface track sensor provides good results that compare well with those of the AWAC in terms of non-directional wave spectra and spectral parameters.

(2) Over the full measurement period, for moderate and Vlarger waves, $\left(\mathrm{H}_{\mathrm{s}} \geq 0.3 \mathrm{~m}\right)$ the $\mathrm{AWAC} \mathrm{H}_{\mathrm{s}}$ values were about $0.02 \mathrm{~m}$ higher than those from the ADCP surface tracking-derived values; this very small difference could be due to the AWAC having a higher noise floor than the RDI ADCP.

(3) The peak periods measured by the Nortek AWAC and the RDI ADCP agreed well over the full period of measurements for moderate and larger wave activity, although the Nortek AWAC exhibited a tendency to select the higher frequency wave peak under bi-modal non-directional wave spectra, due perhaps, to a greater degree of spectral smoothing.

(4) The RDI ADCP directional wave spectra has much better directional resolution in the form of considerably less directional spreading as is evident during the largest storm event of April 28), than that of the AWAC (typically 20 degrees vs. 38 degrees).

Surface tracking is susceptible to false returns from bubble clouds generated by extreme wind-wave conditions. This does not appear to have occurred, to any appreciable degree in this study, and in a 2-month North Sea test only $1.5 \%$ of the AWAC surface track data were questionable (Pedersen, pers. comm.). Nevertheless, this remains an issue for applications in which extreme waves are being generated under very strong winds and levels of air-sea interaction, and/or under a high degree of wave breaking is prevalent.

In an extended use (nearly two years) of RDI directional wave array ADCPs in equatorial west Africa, the instrument demonstrated its ability to measure the directional wave spectra of small amplitude, very long period swell waves out to periods as long as $20-26$ seconds, by means of large $2 \mathrm{~m}$ bin sizes and by extended sampling with a very high duty cycle. The capability to add considerable extra memory and battery resources is crucial to this type of mission.

\section{Acknowledgments}

- Nortek AS: Atle Lohrman, Torstein Pedersen

- RD Instruments: Paul Devine and Darryl Symonds

- The Vancouver Port Authority: Tim Glasheen and Darrell Desjardin

\section{REFERENCES}

[1] E.A. Terray, B.H. Bromley and B. Strong, "Measuring waves and currents with an upward-looking ADCP", Proc. IEEE $6^{\text {th }}$ Working Conference on Current Measurement, 1999, pp. 66-71. ISBN 0-7803-2437-4, IEEE Press.

[2] SonTek, "SonWave-PRO: Directional Wave Data Collection", Sontek Technical Notes, 2001.

[3] L. Gordon and A. Lohrman, "Near-shore Doppler Current Meter Wave Spectra" Proc. Adapted from Proc. ASCE Waves2001 Conference.

[4] T. Pederson, S. Nylund and A. Dolle "Wave Height Measurements Using Acoustic Surface Tracking" Proc. Oceans 2002 Conference, IEEE Press.
[5] B. Strong, B.H. Bromley, E.A, Terray and G. Stone, "The Performance of ADCP-derived direction wave spectra and comparisons with other instruments", Proc.Oceans 2000, IEEE Press.

[6] D. Fissel, R. Birch, K. Borg and H. Melling. "Wave Measurements Using Upward-Looking Sonar for Continental Shelf Applications. Proc. Offshore Tech. Conference (Paper \# 10794), Houston, TX

[7] R. Birch, P.R. Hill, D. Lemon and D. Fissel. "A configurable multi-sensor tripod for the study of near-bottom ocean processes". Proc. Oceans'2003, San Diego CA USA, September 2003, IEEE Press. 